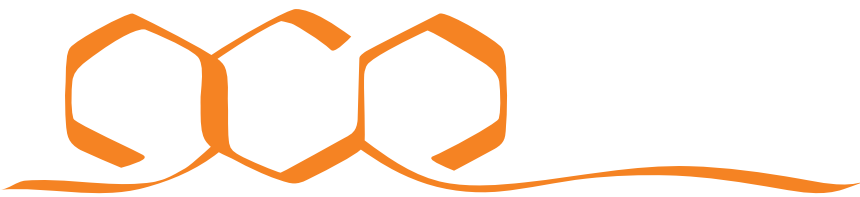 \\ COMMUNICATIONS CHEMISTRY
}

ARTICLE

https://doi-org/10.1038/s42004-018-0097-9

OPEN

\section{Air-stable phosphorus-doped molybdenum nitride for enhanced electrocatalytic hydrogen evolution}

\author{
Junqing Yan', Lingqiao Kong ${ }^{1}$, Yujin $\mathrm{Ji}^{2}$, Youyong $\mathrm{Li}^{2}$, Jai White ${ }^{3}$, Shengzhong (Frank) Liư ${ }^{1,4}$, Xiaopeng Han ${ }^{5}$,
} Shuit-Tong Lee ${ }^{2} \&$ Tianyi $\mathrm{Ma}^{3}$

Molybdenum-based electrocatalysts for hydrogen evolution have been investigated extensively in recent years. However, unlike other non-oxides, molybdenum nitride generally shows a weak preference for hydrogen evolution and low performance owing to surface oxidation and the strong $\mathrm{Mo}-\mathrm{H}$ bond. Here, we prepare an air-stable molybdenum nitride through a multi-step solid-state reaction. We find that a uniformly dispersed mixture of the precursors is optimal for preparation of the electrocatalyst. To further enhance hydrogen evolution performance towards practical device applications, phosphorus doping is carried out, using a few layered black phosphorus source. The phosphorus-doped molybdenum nitride (P-Mo-N) sample catalyzes hydrogen evolution with potentials of 105, 145, and $157 \mathrm{mV}$ at the current densities of 10,50 , and $100 \mathrm{~mA} / \mathrm{cm}^{2}$, respectively, in $0.5 \mathrm{M} \mathrm{H}_{2} \mathrm{SO}_{4}$ solution with a small Tafel slope of $43 \mathrm{mV} / \mathrm{dec}$. Thus it outperforms many of the state-of-art molybdenum-based hydrogen evolution catalysts reported to date.

\footnotetext{
${ }^{1}$ Key Laboratory of Applied Surface and Colloid Chemistry, Ministry of Education, Shaanxi Key Laboratory for Advanced Energy Devices, Shaanxi Engineering Lab for Advanced Energy Technology, School of Materials Science and Engineering, Shaanxi Normal University, Xi'an 710119, People's Republic of China. 2 Institute of Functional Nano and Soft Materials (FUNSOM), Jiangsu Key Laboratory for Carbon-Based Functional Materials and Devices, Soochow University, Suzhou, Jiangsu 215123, People's Republic of China. ${ }^{3}$ Discipline of Chemistry, School of Environmental and Life Sciences, University of Newcastle, Callaghan, NSW, Australia. ${ }^{4}$ iChEM, Dalian Institute of Chemical Physics, Dalian National Laboratory for Clean Energy, Chinese Academy of Sciences, Dalian 116023, People's Republic of China. ${ }^{5}$ School of Materials Science and Engineering, Tianjin Key Laboratory of Composite and Functional Materials, Tianjin University, Tianjin 300072, China. These authors contributed equally: Junqing Yan, Lingqiao Kong, Yujin Ji. Correspondence and requests for materials should be addressed to Y.L. (email: yyli@suda.edu.cn) or to S.L. (email: liusz@snnu.edu.cn) or to T.M. (email: tianyi.ma@newcastle.edu.au)
} 
$\mathrm{H}$ ydrogen evolution reaction (HER) from electrocatalytic water splitting has been regarded as one of the important strategies to solve the world's increasing energy and environment issues ${ }^{1-10}$. Water electrolysis requires a stable electrocatalyst which has the ability to overcome high overpotential and provide efficient activity. To date, Pt-group materials are still the most commonly used catalysts in the commercial HER and there is a demand for a necessary replacement due to their limited supply and high $\operatorname{cost}^{11-20}$. For the sustainable and large-scale application of HER, earth-abundant materials have been under intense investigation in an effort to reach a suitable Pt-like HER performance ${ }^{21-30}$. For the typical HER process, two accepted reaction mechanisms are described, namely the Volmer-Heyrovsky route and Volmer-Tafel route ${ }^{31-34}$. In the Volmer reaction, the formation of $\mathrm{M}-\mathrm{H}$ takes place by proton adsorption on the surface sites of the catalyst. In the subsequent Heyrovsky reaction, one $\mathrm{M}-\mathrm{H}$ undergoes proton-coupled electron transfer reaction to release one $\mathrm{H}_{2}$. Whereas, for the Tafel step, two nearby adsorbed ${ }^{\star} \mathrm{H}(\mathrm{H}-\mathrm{M})$ combine into one $\mathrm{H}_{2}$. Based on the abundant research in recent years, a good Pt-like HER catalyst in acidic solution should exhibit suitable proton adsorption ability and a fast carrier migration ${ }^{21-30}$.

Mo-based materials are widely explored for improved HER performance $21-25,35-40$. In particular, undoped $\mathrm{Mo}_{2} \mathrm{~N}$ has a metallic electronic structure and an excellent $\mathrm{Pt} / \mathrm{Pd}$-like hydrogenation ability. Undoped $\mathrm{Mo}_{2} \mathrm{~N}$ are frequently used in HER, but exhibits moderate performance in comparison with $\mathrm{Mo}_{2} \mathrm{C}$ or $\mathrm{MoP}^{41-43}$. This is caused by the high electronegativity of $\mathrm{N}$ species, which can induce a strong $\mathrm{Mo}-\mathrm{H}$ bond and then weaken the $\mathrm{H}_{2}$ generation rate ${ }^{40}$. To improve the electrocatalytic performance, doping strategies have been widely used ${ }^{4-51}$. The most significant advantage of doping has been to obtain a suitable $\mathrm{M}-\mathrm{H}$ bond with moderate strength $44,46,50,51$. Moreover, $\mathrm{N}$ doping is reported to improve the electrocatalytic hydrogen performance of MoP by reducing the electrical resistance, increasing the number and quality of active sites ${ }^{52}$. The non-metal constituents, nitrogen $(\mathrm{N})$ and phosphorous $(\mathrm{P})$ belong to the same group family and thus have a similar electronic structure. However, phosphorus is more electronegative (2.19) than nitrogen (3.04), and thus, the replacement of $\mathrm{N}$ by $\mathrm{P}$ may lead to a weakened $\mathrm{M}-\mathrm{H}$ bond ${ }^{50,51}$. However, thus far, P-doped molybdenum nitride for improving HER performance has not been studied in detail.

One key challenge for obtaining a high HER activity is to locate the electroactive sites of catalysts. The edge sites exposed doped elements or vacancies are reported to be responsible for the enhanced reaction performance $e^{50-55}$. Increasing the number of reaction sites has been one major explored strategy. For the synthesis of $\mathrm{Mo}_{2} \mathrm{~N}$, ammonia reduction of molybdenum oxide is widely used through high-temperature calcination, which could induce the expected aggregation, thus reducing the exposed reaction sites and weakening the corresponding electrocatalytic activity. However, the releasing of the in situ generated gas can promote the formation of holes or disordered lattice structures, thereby avoiding the aggregation and increasing active sites ${ }^{53,55}$.

Herein, we report a two-step synthesis strategy to prepare Pdoped $\mathrm{Mo}_{2} \mathrm{~N}$. The mixture of $\mathrm{MoO}_{3}$ and ethanediamine are first treated by high-strength solid-phase grinding and then calcinated in an $\mathrm{N}_{2}$ atmosphere. $\mathrm{Mo}_{2} \mathrm{~N}$ is obtained with abundant exposed grain-boundary sites $(\mathrm{Mo}-\mathrm{N})$. Few layered black phosphorus (BP) is used for P doping via vacuum stirring of the BP and $\mathrm{Mo}_{2} \mathrm{~N}$ mixture, followed by calcination to obtain $\mathrm{P}-\mathrm{Mo}_{2} \mathrm{~N}$ $(\mathrm{P}-\mathrm{Mo}-\mathrm{N})$. The obtained samples of $\mathrm{Mo}-\mathrm{N}$ and $\mathrm{P}-\mathrm{Mo}-\mathrm{N}$ display notable electrocatalytic HER performance and stability, even at a high current density of $160 \mathrm{~mA} / \mathrm{cm}^{2}$.

\section{Results}

Synthesis of Mo-N and P-Mo-N. First, $\mathrm{Mo}_{2} \mathrm{~N}\left(\mathrm{Mo}_{2} \mathrm{~N}-\mathrm{r}\right)$ was synthesized from the reduction reaction of $\mathrm{MoO}_{3}$ by the release of in situ $\mathrm{NH}_{3}$ similar to previous work conducted using melamine as the $\mathrm{NH}_{3}$ source ${ }^{39}$. Solid-state reaction has been used previously to generate samples with numerous holes and vacancies due to the in situ release of gases ${ }^{53,55}$. Owing to its active character, $\mathrm{Mo}_{2} \mathrm{~N}$ can be oxidized easily at ambient conditions. Supplementary Figure 1a shows the photograph of the autoignition of $\mathrm{Mo}_{2} \mathrm{~N}-\mathrm{r}$. Such an active material owns so many surface oxidation states that its catalytic activity is relatively low ${ }^{41-43}$. More exposed Mo sites may be responsible for the above active phenomenon of autoignition. To obtain a relatively stable sample, ethanediamine was used to generate in situ $\mathrm{NH}_{3}$. This was also expected to change the crystal faces via the release of gases during its decomposition. The layered $\mathrm{MoO}_{3}$ and ethanediamine (mass ratio: 1:2) were mixed thoroughly by a ball grinder (Fig. 1a). The mixture was then calcined in an $\mathrm{N}_{2}$ atmosphere. After that, a layered graphite-like sample (Mo-N-2) without autoignition characteristics was obtained as shown in Supplementary Figure $1 \mathrm{~b}$. The crystal structure was confirmed to be $\mathrm{Mo}_{2} \mathrm{~N}$ from the X-ray diffraction (XRD) measurement (Supplementary Figure 1c). The direct appearance of the two samples was tested by scanning electron microscopy (SEM). As shown in Supplementary Figure 2, $\mathrm{Mo}_{2} \mathrm{~N}-\mathrm{r}$ and $\mathrm{Mo}-\mathrm{N}-2$ give the aggregated and layered structures, respectively. The samples from the two different processes were measured by transmission electron microscope (TEM) to further check their morphologies. $\mathrm{Mo}_{2} \mathrm{~N}-\mathrm{r}$ and Mo-N-2 both show the layered structure; however, the ethanediamine-induced sample presents some obvious particles (Supplementary Figure 3). The high resolution TEM in Supplementary Figure 4 shows the detailed difference of the two samples. $\mathrm{Mo}_{2} \mathrm{~N}-\mathrm{r}$ shows the typical continuous lattice structure while Mo-N-2 gives obvious crossed lattice fringes, that is, for the Mo-N-2 sample, the formed nanoparticles combine together to maintain the apparent nanosheet morphology (Supplementary Figure 2). This suggests that the ethanediamine-based solid-state reaction can induce the dismemberment of layered $\mathrm{MoO}_{3}$ to form nanoparticles, and then generate more grain-boundaries under the releasing of gases. To get the suitable grain-boundary and prevent aggregation, the amount of ethanediamine was tested. The mass ratios of $\mathrm{MoO}_{3}$ to ethanediamine were increased from $1: 3$ to $1: 4$ to $1: 5$. Supplementary Figure 5 shows the corresponding XRD results of obtained samples (Mo-N-n). Only the $\mathrm{Mo}_{2} \mathrm{~N}$ phase can be found in three samples indicating no noticeable change to the crystal lattice structure even at the highest ratios (Supplementary Figure 5a). The TEM images show obvious grain-boundaries, as well as some detectable lattice distortion (Supplementary Figure 5b-d). Please note that all the synthesized samples of Mo-N-x present the appearance of nanosheet, which is composed of nanoparticles.

The electrocatalytic hydrogen generation from water splitting in $0.5 \mathrm{M} \mathrm{H}_{2} \mathrm{SO}_{4}$ solution was carried out for detecting the activity of the obtained samples. The Mo-N-n samples give an enhanced HER performance obviously compared with $\mathrm{Mo}_{2} \mathrm{~N}-\mathrm{r}$ (Supplementary Figure 6), suggesting that the ethanediamine-driven $\mathrm{Mo}_{2} \mathrm{~N}$ samples have a dominant $\mathrm{Mo}-\mathrm{H}$ adsorption-desorption performance. More grain-boundary sites, i.e. more nanoparticle formation from the sufficient reduction reaction between ethanediamine and $\mathrm{MoO}_{3}$ is the internal origin ${ }^{53,55}$. With increasing ethanediamine content, the HER performance increases accordingly. For the samples obtained from $\mathrm{MoO}_{3}$ and ethanediamine mass ratio: $1: 4$ and 1:5 (Mo-N-4 and Mo-N-5) show a similar activity. Therefore, Mo-N-4 (Mo-N) was selected for further research.

At the second step, $\mathrm{P}$ doping was carried out to further modulate their HER performance as show in Fig. 1b-d. The Mo-N sample and layered black phosphorus (BP $)^{56,57}$ were used as the precursors. Few layered BP is not stable in air and can be oxidized to $\mathrm{PO}_{x}$ species, which can be reduced and doped into $\mathrm{Mo}_{2} \mathrm{~N}$ lattices. Moreover, few-layer BPs still keep the structural 


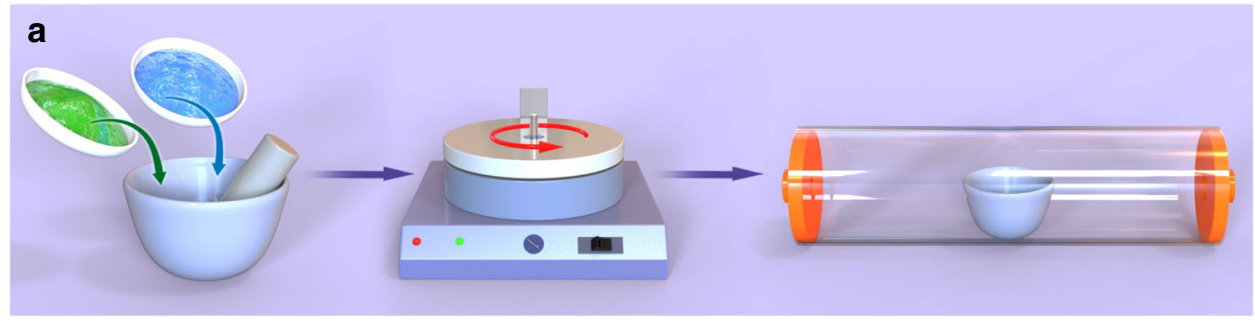

b
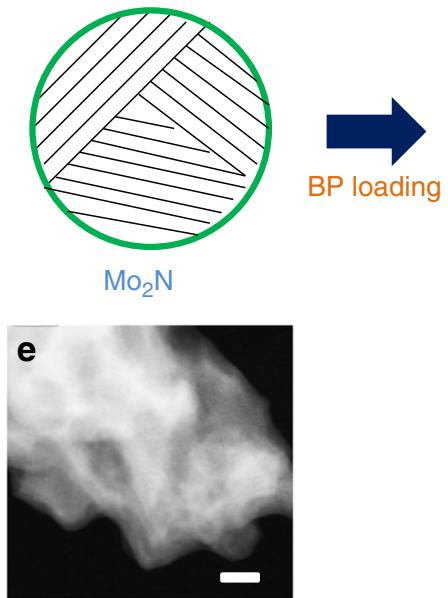

c
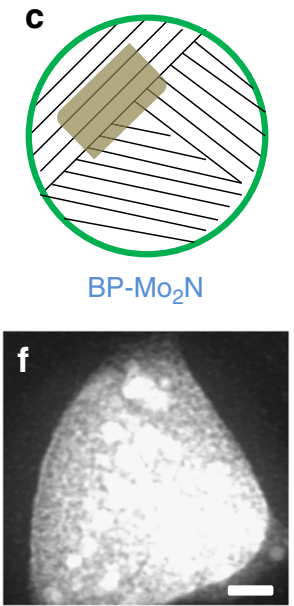

d
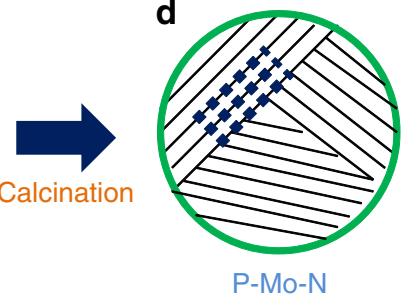

g

Fig. 1 Synthesis of $\mathrm{Mo}_{2} \mathrm{~N}$ and $\mathrm{P}-\mathrm{Mo}_{2} \mathrm{~N}$. a Schematic illustration of the synthesis of $\mathrm{Mo}_{2} \mathrm{~N}$, two precursors in a are ethanediamine and $\mathrm{MoO}_{3}$, respectively. b The surface model of $\mathrm{Mo}_{2} \mathrm{~N}$, which is used for $\mathrm{BP}$ loading, that is, $\mathrm{BP}$ and $\mathrm{Mo}_{2} \mathrm{~N}$ are treated by vacuum stirring. $\mathbf{c}$ The surface model of $\mathrm{BP}-\mathrm{Mo} \mathrm{N}_{2} \mathrm{~N}$, the gray part is loaded BP. $\mathbf{d}$ The model of $\mathrm{P}$ doped $\mathrm{Mo}_{2} \mathrm{~N}$ lattice structure, the blue dots are $\mathrm{P}$ element in the lattice. e-g The corresponding TEM images of $\mathrm{Mo}_{2} \mathrm{~N}$, $\mathrm{BP}-\mathrm{Mo}_{2} \mathrm{~N}$, and P-Mo-N, respectively. The scale bars are 50, 20, and $50 \mathrm{~nm}$ in $\mathbf{e}, \mathbf{f}$, and $\mathbf{g}$, respectively. The white spots in TEM image of BP-Mo $2 \mathrm{~N}$ is the BP, which disappears after the calcination treatment as shown in $\mathrm{P}-\mathrm{Mo}-\mathrm{N}$ image, suggesting the $\mathrm{P}$ doping into the lattice of $\mathrm{Mo}_{2} \mathrm{~N}$

integrity of $\mathrm{Mo}_{2} \mathrm{~N}$ during the $\mathrm{P}$ doping process. Supplementary Figure 7 shows the typical TEM images of $\mathrm{BP}$, the layered structure can be detected. The mixture of the Mo-N sample and $\mathrm{BP}$ was collected after about $3 \mathrm{~h}$ vacuum-stirring with the $\mathrm{BP}$ being loaded onto the surface of Mo-N (Fig. 1c). After storage in air for 1 day, the sample was treated by calcination with the adding of ethanediamine in an $\mathrm{N}_{2}$ atmosphere to finalize the $\mathrm{P}$ doping (Fig. 1d). Figure 1 also shows the corresponding TEM images of the Mo-N samples. Clearly, the image of the P doped sample (Supplementary Figure 8) shows a disordered lattice structure, because of the large ionic radius of P. To confirm the negligible impact of secondary calcination on the HER performance, the reference sample without BP addition was synthesized. As given in Supplementary Figure 9, the XRD pattern does not show an obvious change compared with the initial one (Supplementary Figure 9a). The HER activity also remains unchanged (Supplementary Figure 9b). The obtained sample was named as $\mathrm{P}-\mathrm{Mo}-\mathrm{N}$ for the following discussion, in which the $\mathrm{P}$ content was $10 \mathrm{wt} . \%$ (Please note that the $\mathrm{P}$ content of $\mathrm{P}-\mathrm{Mo}-\mathrm{N}$ samples was detected by X-ray photoelectron spectroscopy (XPS) measurements and is semi-quantitative). The specific surface areas of the samples were further measured by $\mathrm{N}_{2}$ adsorption-desorption method, calculated by multiple spot Brunauer-Emmett-Teller (BET) theory. As shown in Supplementary Figure 10, the BET surface areas of $\mathrm{Mo}_{2} \mathrm{~N}-\mathrm{r}, \mathrm{Mo}-\mathrm{N}$, and $\mathrm{P}-\mathrm{Mo}-\mathrm{N}$ are $4.48,5.54$, and $5.38 \mathrm{~m}^{2} / \mathrm{g}$, respectively, further confirming that the ethanediamine-driven method can avoid the aggregation.

Characterization of P-Mo-N. Figure 2a shows the XRD pattern of $\mathrm{P}-\mathrm{Mo}-\mathrm{N}$ sample, four typical peaks are located at 2 theta of $37^{\circ}, 41^{\circ}, 62^{\circ}$, and $74.5^{\circ}$, which can be attributed to (112), (200), (220), and (312) of tetragonal $\mathrm{Mo}_{2} \mathrm{~N}$ (PDF: 25-1368). Compared with the initial Mo-N sample, no obvious change of peak position and intensity suggests that the secondary calcination of $\mathrm{P}$ doping hardly changes the crystalline structure. From the SEM images in Fig. $2 \mathrm{~b}$ and Supplementary Figure 11, the Mo-N and P-Mo-N samples give a nanosheet-like appearance (Supplementary Figure 11a-b). In the magnified SEM in Fig. 2b and Supplementary Figure 11c, nanoparticles with a size of ca. $8 \mathrm{~nm}$ can be found, evidencing that the rough nanosheets of $\mathrm{Mo}-\mathrm{N}$ and $\mathrm{P}-\mathrm{Mo}-\mathrm{N}$ samples are formed by nano-sized particles. The TEM image of $\mathrm{P}-\mathrm{Mo}-\mathrm{N}$ was shown in Fig. 2c. Clearly, the nanoparticles can be found along the nanosheet edge. The inset shows the corresponding electron diffraction spectrum (EDS), revealing the typical four crystal faces, which is consistent with the XRD pattern (Fig. 2a). We also presented the TEM images of the reference P-Mo-N samples with 9.5 wt.\% and 10.5 wt.\% P doping. As shown in Supplementary Figure 12, TEM images similar to that of the $10 \mathrm{wt} . \%$ sample $\mathrm{P}-\mathrm{Mo}-\mathrm{N}$ can be found, with both of them giving the rough sheet surface. The corresponding EDS results suggest that the $\mathrm{Mo}_{2} \mathrm{~N}$ phase was obtained and the $\mathrm{P}$ content in this range hardly affects the final product formation. The HRTEM image of the P-Mo-N sample in Fig. 2d further suggests the existence of nanoparticles. The obvious grain boundaries can be found and two interplanar crystal spacing values are measured to be 0.24 and $0.21 \mathrm{~nm}$, which can be assigned to the (112) and (200) crystal faces, respectively. The disordered lattice fringes can also be detected. Supplementary Figure 13 gives the corresponding HRTEM images of the reference P doped samples with similar results. Figure $2 \mathrm{e}$ gives the element mapping result of $\mathrm{P}-\mathrm{Mo}-\mathrm{N}$ sample. Clearly, the elements of Mo, N, and P show uniform distribution. We also give the element mapping of the reference sample of Mo-N as shown in Supplementary Figure 14, only two elements of Mo and $\mathrm{N}$ can be detected.

XPS was further carried out for obtaining more information about the surface and sub-surface states. In the Mo $3 \mathrm{~d}$ region for 

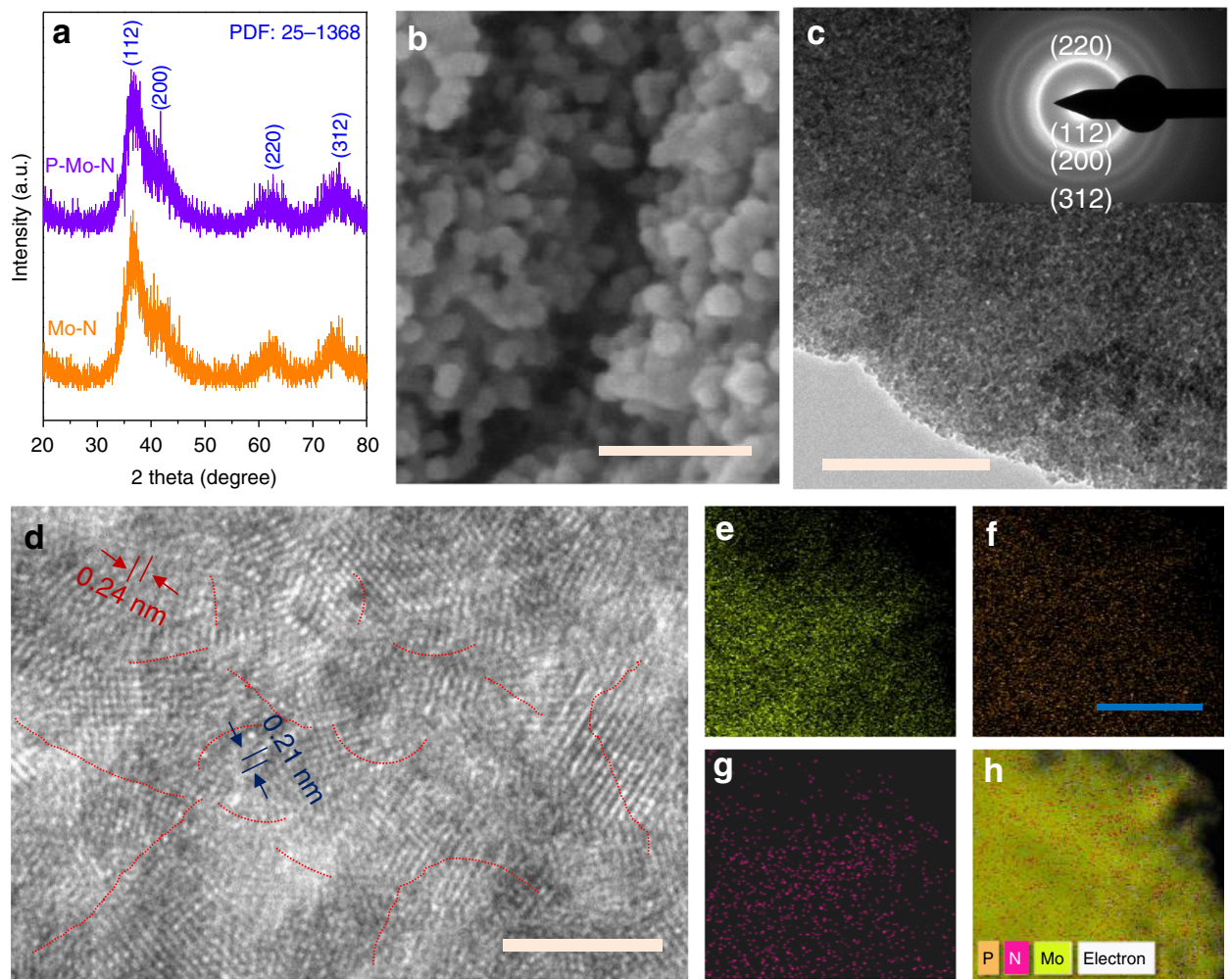

Fig. 2 Physical characterization of P-Mo-N. a XRD pattern of the Mo-N and P-Mo-N, the PDF number (25-1368) of standard Mo 2 N is shown. b SEM image of P-Mo-N sample, scale bar: $50 \mathrm{~nm}$. c TEM image of P-Mo-N, the scale bar is $50 \mathrm{~nm}$, the inset shows the corresponding EDS result with the crystal indices. d HRTEM image of P-Mo-N, the obvious grain-boundaries are marked by red dots, two interplanar spacing values of 0.24 and $0.21 \mathrm{~nm}$ are also shown, scale bar: $1 \mathrm{~nm}$; The element mapping of P-Mo-N sample, e Mo element, $\mathbf{f} \mathrm{N}$ element, $\mathbf{g} \mathrm{P}$ element, and $\mathbf{h}$ the mixed result, scale bar: $50 \mathrm{~nm}$

the Mo-N and P-Mo-N as shown in Supplementary Figure 15a, for the Mo-N sample, the Mo 3d core level spectrum can be fitted into four peaks, i.e. two pairs of 229.2 and $232.2 \mathrm{eV}, 233.2$, and $236.2 \mathrm{eV}$. The first pair is attributed to Mo-N bonds, in which the high binding energy value is ascribed to $\mathrm{MoO}_{3}{ }^{58}$, and the existence of oxide suggests the oxidization of the surface Mo species. For the $\mathrm{P}$ doped $\mathrm{Mo}_{2} \mathrm{~N}$, a pair of new peaks located at 230.1 and $232.7 \mathrm{eV}$ can be detected and can be assigned to the Mo-P peaks ${ }^{59,60}$, confirming that the $\mathrm{P}$ has been doped into the $\mathrm{Mo}_{2} \mathrm{~N}$ lattice. Moreover, the positions of Mo $3 \mathrm{~d}$ peaks for Mo-N and $\mathrm{Mo}-\mathrm{O}$ bonds show a slight shift towards the low binding energy region as shown in Supplementary Table 1. This phenomenon may originate from the $\mathrm{P}$ doping that can share the Mo binding bond and then weaken their bonding energy. Note that the full width at half maximum of the Mo-N bonds for the two samples of Mo-N and P-Mo-N is the same $(1 \mathrm{eV})$, further suggesting the formation of the Mo-P bond after $\mathrm{P}$ doping. For N $1 \mathrm{~s}$ XPS spectrum in Supplementary Figure 15b, two main peaks can be found for both Mo-N and P-Mo-N. The first peak located at $395.1 \mathrm{eV}$ belongs to the Mo 3p core level, and the second peak at $398.3 \mathrm{eV}$ is attributable to $\mathrm{Mo}-\mathrm{N}$ bond. For $\mathrm{P}-\mathrm{Mo}-\mathrm{N}$, the $\mathrm{N} 1 \mathrm{~s}$ peak gives a noticeable shift to $398.26 \mathrm{eV}$ (398.3 eV of bare Mo-N), suggesting that the $\mathrm{P}$ element has been doped into the $\mathrm{Mo}_{2} \mathrm{~N}$ lattice by replacing one $\mathrm{N}$ element. For the $\mathrm{P} 2 \mathrm{p}$ XPS spectrum of $\mathrm{P}-\mathrm{Mo}-\mathrm{N}$ in Supplementary Figure 15c, one main peak can be fitted into two peaks, located at 130.1 and 131.2 $\mathrm{eV}$. This low binding energy peak can be assigned to the Mo-P bond. Furthermore, 1 weak peak at ca. $133.6 \mathrm{eV}$ attributable to $\mathrm{PO}_{x}$ can also be detected. The BP was reduced by urea during the calcination and then most of the elemental $\mathrm{P}$ was in situ doped into the lattice of formed $\mathrm{Mo}_{2} \mathrm{~N}$. To confirm the above assumption, two steps of $\mathrm{P}$ doping process were picked out for checking the change of Mo, N, and $\mathrm{P}$ valence states. The first step was the original sample i.e. $\mathrm{PO}_{x} / \mathrm{Mo}_{2} \mathrm{~N}$; this sample was treated about $1 \mathrm{~h}$ with the existence of urea and $\mathrm{N}_{2}$ and denoted as $\mathrm{PO}_{x} /$ $\mathrm{P}-\mathrm{Mo}_{2} \mathrm{~N}$. Supplementary Figure 16 shows the corresponding XPS results. For the Mo 3d XPS spectrum (Supplementary Figure 16a), like the pure $\mathrm{Mo}_{2} \mathrm{~N}$, the sample of $\mathrm{PO}_{x} / \mathrm{Mo}_{2} \mathrm{~N}$ shows the typical four peaks attributable to the $\mathrm{Mo}-\mathrm{N}$ and $\mathrm{Mo}-\mathrm{O}\left(\mathrm{MoO}_{3}\right)$ bonds. However, the $\mathrm{PO}_{x} / \mathrm{P}-\mathrm{Mo}_{2} \mathrm{~N}$ sample, which is not a completely reduced sample, shows a different result compared with the initial sample. At the binding energy of ca. 230.0 and $232.6 \mathrm{eV}$, two weak peaks, which can be assigned to the formation of $\mathrm{MoP}_{x}$, are found, suggesting that a proportion of the used $\mathrm{P}$ has been doped into the $\mathrm{Mo}_{2} \mathrm{~N}$ lattice. For the $\mathrm{N} 1 \mathrm{~s}$ XPS spectra, the similar results compared with the patterns in Supplementary Figure 16b can be found. However, the $\mathrm{N} 1 \mathrm{~s}$ binding energy of $\mathrm{PO}_{x} / \mathrm{P}-\mathrm{Mo}_{2} \mathrm{~N}$ sample is ca. $298.28 \mathrm{eV}$, slightly smaller than that of $\mathrm{PO}_{x} / \mathrm{Mo}_{2} \mathrm{~N}$ $(398.3 \mathrm{eV})$ and higher than that of P-Mo-N (398.26 eV), further confirming the successful $\mathrm{P}$ doping into the $\mathrm{Mo}_{2} \mathrm{~N}$ lattice. For the P 2p XPS spectrum in Supplementary Figure 16c, the sample of $\mathrm{PO}_{x} / \mathrm{Mo}_{2} \mathrm{~N}$ exhibits a strong peak located at $133.7 \mathrm{eV}$, which comes from the surface of $\mathrm{PO}_{x}$ species. Meanwhile, for $\mathrm{PO}_{x} /$ $\mathrm{P}-\mathrm{Mo}_{2} \mathrm{~N}$, the peak centered at $133.7 \mathrm{eV}$ is weakened and two new peaks (130.0 and $131.1 \mathrm{eV}$ ) appear, suggesting the doped $\mathrm{P}$ element exists at the low valance state. Based on the above analysis, Supplementary Figure $16 \mathrm{~d}$ gives the models of the $\mathrm{P}$ doping process: at the first stage, the $\mathrm{PO}_{x}$ species is only adsorbed onto the surface of $\mathrm{Mo}_{2} \mathrm{~N}$; during calcination, the $\mathrm{P}$ element of $\mathrm{PO}_{x}$ will be reduced into the low valance $\mathrm{P}$ and doped into the lattice of $\mathrm{Mo}_{2} \mathrm{~N}$; after the calcination $(2 \mathrm{~h})$, all the $\mathrm{P}$ was reduced and in situ incorporated into the $\mathrm{Mo}_{2} \mathrm{~N}$ phase.

As discussed earlier, to further confirm the present samples are not formed by simple physical aggregation, the Mo-N and 
$\mathrm{P}-\mathrm{Mo}-\mathrm{N}$ were treated by $12 \mathrm{~h}$ ultrasound. After the centrifugation, the supernate was chosen for the TEM measurement. As shown in Supplementary Figure 17, the two samples both show unchanged morphology. The crystal boundaries can be still found, suggesting that the different nanoparticles are fastened together with each other strongly, not a physical mixture. During the synthesis process, the ethanediamine and $\mathrm{MoO}_{3}$ were grinded thoroughly and then a uniform mixture was obtained. Under the calcination, ethanediamine released $\mathrm{NH}_{3}$ and other gases, which reacted with $\mathrm{MoO}_{3}$ to form $\mathrm{Mo}_{2} \mathrm{~N}$. During the reaction, the layered structure of $\mathrm{MoO}_{3}$ was destroyed with the formation of $\mathrm{Mo}_{2} \mathrm{~N}$ nanoparticles. The calcination further combined the particles with many crystal boundaries with the disordered crystal lattices obtained. To the best of our knowledge, it is the first time to report one stable $\mathrm{Mo}_{2} \mathrm{~N}$ sample in air, and the exposed different crystal surfaces may be responsible for the above novel phenomena i.e. air-stable and high HER performance.

HER performance of Mo-N and P-Mo-N. Most of electrocatalytic HER among Mo-based samples reported to date investigate their carbides or phosphates in acidic media. Owing to the relative strong electronegativity of $\mathrm{N}$, the molybdenum nitride samples exhibited a low activity 37,39 . Herein, the capability of HER electrocatalysis of $\mathrm{P}-\mathrm{Mo}-\mathrm{N}$ sample was explored in $0.5 \mathrm{M}$ $\mathrm{H}_{2} \mathrm{SO}_{4}$ solution at ambient temperature. The samples were prepared into a homogeneous ink with Nafion solution and isopropanol and then dropped onto the glassy carbon electrodes for the HER measurements. The potentials obtained from the measurements were converted to values relative to a reversible hydrogen electrode (RHE). Figure 3a shows the relevant polarization curves of different electrodes, including $\mathrm{P}-\mathrm{Mo}-\mathrm{N}$ and the reference samples of $\mathrm{Mo}_{2} \mathrm{~N}-\mathrm{r}$ and $\mathrm{Mo}-\mathrm{N}$. The purchased $20 \% \mathrm{Pt} /$ $\mathrm{C}$ electrode was also used as a standard sample. Obviously, the activity trend is as follows: $\mathrm{Mo}_{2} \mathrm{~N}-\mathrm{r}<\mathrm{Mo}-\mathrm{N}<\mathrm{P}-\mathrm{Mo}-\mathrm{N}<\mathrm{Pt} / \mathrm{C}$, with the onset potentials (defined as the overpotential at current density of $-1 \mathrm{~mA} \mathrm{~cm}^{-2}$ ) of $74,73,28$, and $17 \mathrm{mV}$, respectively. Moreover, compared to the reference $\mathrm{Mo}_{2} \mathrm{~N}-\mathrm{r}$ and $\mathrm{Mo}-\mathrm{N}$, the $\mathrm{P}$ doped sample presents a sharply enhanced current response at low applied potentials, suggesting that the $\mathrm{P}$ doping can boost a better proton transfer and adsorption-desorption processes. Then the potentials at four current density values of $10,50,100$, and $150 \mathrm{~mA} / \mathrm{cm}^{2}$ were compared as shown in Fig. $3 \mathrm{~b} . \mathrm{Mo}_{2} \mathrm{~N}-\mathrm{r}$ and Mo-N both present relatively high potentials, larger than $200 \mathrm{mV}$. For the $\mathrm{P}$ doped $\mathrm{Mo}_{2} \mathrm{~N}$, a sharp decrease can be detected in comparison to the two undoped samples. In details, the $\mathrm{P}-\mathrm{Mo}-\mathrm{N}$ sample gives the potentials of $105,145,157$, and 164 $\mathrm{mV}$ at $10,50,100$, and $150 \mathrm{~mA} / \mathrm{cm}^{2}$, respectively. As a contrast, the $\mathrm{Pt} / \mathrm{C}$ sample exhibits a potential of $47 \mathrm{mV}$ at the $10 \mathrm{~mA} / \mathrm{cm}^{2}$ condition, similar to the reported values in the literature $8,42,44$. Figure $3 \mathrm{c}$ gives the corresponding Tafel slope results of the samples under study. The referenced commercial $\mathrm{Pt} / \mathrm{C}$ sample gives the smallest slope of $37 \mathrm{mV} / \mathrm{dec}$, followed by $\mathrm{P}-\mathrm{Mo}-\mathrm{N}$ of 43 $\mathrm{mV} / \mathrm{dec}, \mathrm{Mo}-\mathrm{N}$ of $76 \mathrm{mV} / \mathrm{dec}$, and $\mathrm{Mo}_{2} \mathrm{~N}-\mathrm{r}$ of $71 \mathrm{mV} / \mathrm{dec}$. A slope larger than $30 \mathrm{mV} / \mathrm{dec}$ for the $\mathrm{P}-\mathrm{Mo}-\mathrm{N}$ sample suggests a Volmer-Heyrovsky route for HER, $10,11,14$. The exchange current density $\left(j_{0}\right)$, the most inherent measure of HER activity, was also calculated based on the Tafel equations (Supplementary Table 2). The $j_{0}$ values of $\mathrm{P}-\mathrm{Mo}-\mathrm{N}, \mathrm{Mo}-\mathrm{N}$ and $\mathrm{Mo}_{2} \mathrm{~N}-\mathrm{r}$ are $0.02,0.0052$, and $6.67 \times 10^{-6} \mathrm{~mA} / \mathrm{cm}^{2}$, respectively. The $\mathrm{P}$ doping can facilitate a large exchange current density, increasing by a factor of 4 in comparison with the undoped samples. Supplementary Table 3 gives the direct activity comparison of $\mathrm{P}-\mathrm{Mo}-\mathrm{N}$ with the Mobased samples recently reported in the literature. Obviously, our $\mathrm{P}-\mathrm{Mo}-\mathrm{N}$ sample gave the best HER performance in $0.5 \mathrm{M} \mathrm{H}_{2} \mathrm{SO}_{4}$ solution in terms of current density and Tafel slope. To further confirm the reaction sites to be the $\mathrm{P}$ sites on the surface of $\mathrm{Mo}_{2} \mathrm{~N}$, the MoP and $\mathrm{N}$ doped MoP were also synthesized ${ }^{52}$.
Supplementary Figure 18a gave the XRD patterns of MoP (PDF: 24-0771) and Supplementary Figure 18b showed the corresponding HER performance. Clearly, although $\mathrm{Mo}_{2} \mathrm{~N}$ shows the lowest HER activity, the $\mathrm{P}$ doped $\mathrm{Mo}_{2} \mathrm{~N}$ gives the best.

The electrochemical impedance spectroscopy (EIS) was carried out to probe charge transfer processes on the catalysts in $0.5 \mathrm{M}$ $\mathrm{H}_{2} \mathrm{SO}_{4}$ solution. Figure $3 \mathrm{~d}$ shows the Nyquist plots of the samples of $\mathrm{Mo}_{2} \mathrm{~N}-\mathrm{r}, \mathrm{Mo}-\mathrm{N}$ and $\mathrm{P}-\mathrm{Mo}-\mathrm{N}$ under a $250 \mathrm{mV}$ potential condition. Clearly, the $\mathrm{P}$ doped sample gives the smallest circular arc, followed by $\mathrm{Mo}-\mathrm{N}, \mathrm{Mo}_{2} \mathrm{~N}-\mathrm{r}$, suggesting that the $\mathrm{P}-\mathrm{Mo}-\mathrm{N}$ has a relative small carrier migration resistance. Supplementary Figure 19 shows the Nyquist plot of reference $\mathrm{Pt} / \mathrm{C}$ sample and the corresponding fitted circuit diagram. The $\mathrm{R}_{\Omega}$ and $\mathrm{R}_{\mathrm{ct}}$ mean the electrode resistance and carrier transfer resistance across the catalyst/solution interface, respectively. The Warburg and CPE are diffusion resistance and the constant phase element, both are out of consideration owing to the limited applying frequency in our present work. Supplementary Table 4 shows the corresponding fitted results of $R_{\Omega}$ and $R_{c t}$ of the three samples. Typically, all the samples give a similar $R_{\Omega}$ value $(0.15 \mathrm{ohm})$, suggesting the resistance of catalyst/electrode is almost the same. Regarding $R_{c t}$, the three samples of $\mathrm{Mo}_{2} \mathrm{~N}-\mathrm{r}, \mathrm{Mo}-\mathrm{N}$ and $\mathrm{P}-\mathrm{Mo}-\mathrm{N}$ give decreased values from 111.2 , to 50.02 to $14.69 \mathrm{ohm}$, respectively, confirming that the $\mathrm{P}$ doping can induce a suitable proton adsorption-desorption, and then decrease the resistance of the solid/solution interface. To get more information about the catalyst/solution interface, double-layer capacitance $\left(\mathrm{C}_{\mathrm{dl}}\right)$ calculations were carried out using cyclic voltammetry $(\mathrm{CV})$ to roughly evaluate their effective electrochemical active surface area on $\mathrm{Mo}_{2} \mathrm{~N}-\mathrm{r}, \mathrm{Mo}-\mathrm{N}$ and $\mathrm{P}-\mathrm{Mo}-\mathrm{N}$. The $\mathrm{CV}$ was tested with a potential range of -0.2 to $0 \mathrm{~V}$ vs $\mathrm{RHE}$ at different scan rates, and the $\Delta \mathrm{j}$ at $-0.1 \mathrm{~V}$ vs scan rate was plotted. The slope was supposed to be twice that of the $\mathrm{C}_{\mathrm{dl}} 44,60$. Our results (Supplementary Figure 20) reveal a considerably larger $\mathrm{C}_{\mathrm{dl}}$ of the $\mathrm{P}-\mathrm{Mo}-\mathrm{N}$ sample $\left(275 \mathrm{mF} \mathrm{cm}^{-2}\right)$ compared with bare $\mathrm{Mo}-\mathrm{N}\left(115 \mathrm{mF} \mathrm{cm}^{-2}\right)$ and the referenced $\mathrm{Mo}_{2} \mathrm{~N}-\mathrm{r}\left(60 \mathrm{mF} \mathrm{cm}{ }^{-2}\right)$, indicating more accessible electroactive sites created by $\mathrm{P}$ doping in the $\mathrm{Mo}_{2} \mathrm{~N}$ network. The $\mathrm{P}$ doping was achieved by BP loading first and then calcination, thus more $\mathrm{P}$ element was confined into the surface lattice, which may contribute to the small carrier migration resistance across the catalyst/solution interface and a large $\mathrm{C}_{\mathrm{dl}}$.

Moreover, the operating stability of the catalyst is of great concern in the real industrial application. The polarization curve after 10,000 cycles was performed on $\mathrm{P}-\mathrm{Mo}-\mathrm{N}$ catalyst in the 0.5 $\mathrm{M} \mathrm{H}_{2} \mathrm{SO}_{4}$ solution. As given in Fig. $3 \mathrm{e}$, negligible change can be found before and after the continuous cycle test. The chronoamperometry $(\mathrm{j}-\mathrm{t})$ response was further carried out under three potentials of 145,157 , and $164 \mathrm{mV}$. The $j$ responses with the corresponding values of 50,100 , and $150 \mathrm{~mA} / \mathrm{cm}^{2}$ give no obvious decrease or increase during the continuous $12 \mathrm{~h}$ measurement (Fig. 3f). The EIS spectrum and XRD pattern of the P-Mo-N catalyst were further tested as given in Supplementary Figure 21. No change to the resistance and phase can be found, further suggesting a good stability of P-Mo-N catalyst. Supplementary Figure 22 gives the contrastive HRTEM images with no change. Moreover, the electrocatalytic HER activity after 3 months (storing in a sample tube without vacuum treatment) was also conducted. Almost no shift of polarization curves after one and three months (Supplementary Figure 23). The effect of $\mathrm{P}$ content for HER performance was verified. As given in Supplementary Figure 24a, the $9.5 \mathrm{wt} \%, 10 \mathrm{wt} \%$, and $10.5 \mathrm{wt} \%$ sample show the similar XRD pattern, confirming that the $\mathrm{P}$ content in these three values does not change the phase of $\mathrm{Mo}_{2} \mathrm{~N}$. The HER activity in Supplementary Figure $24 \mathrm{~b}$ confirms that the 10 wt.\% $\mathrm{P}$ doping can induce the best electrocatalytic performance. 

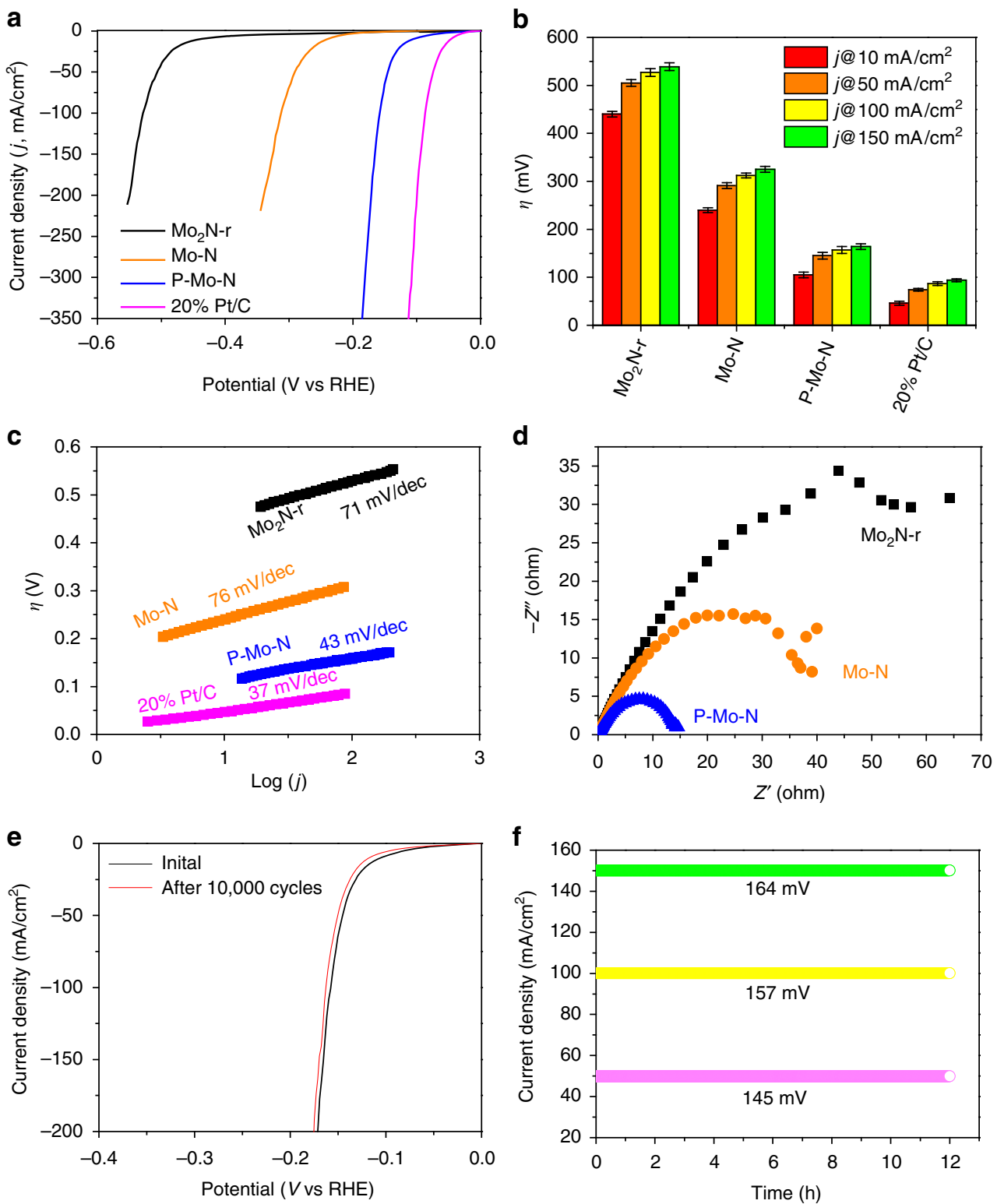

Fig. 3 HER electrocatalysis of $\mathrm{Mo}_{2} \mathrm{~N}-\mathrm{r}, \mathrm{Mo}-\mathrm{N}, \mathrm{P}-\mathrm{Mo}-\mathrm{N}$ and reference $20 \% \mathrm{Pt} / \mathrm{C}$. a Polarization curves recorded on glassy carbon electrodes, the catalyst loading was $0.2 \mathrm{mg} / \mathrm{cm}^{2}$. b The corresponding overpotentials of the samples under the current density (j) values of 10, 50, 100, and 150 mA/ $\mathrm{cm}^{2}$. Please note that every sample was tested 10 times and then the corresponding standard deviation value was used for the error bar. c The Tafel plots, derivate from the polarization curves. $\mathbf{d}$ The electrochemical impedance spectra (EIS) of $\mathrm{Mo}_{2} \mathrm{~N}-\mathrm{r}$, Mo-N, and P-Mo-N samples. e Durability test of the P-Mo-N catalyst, showing the results of initial and 10,000 cycles. $\mathbf{f}$ The current density vs time response results under three potentials of 145,157 , and $164 \mathrm{mV} 0.5 \mathrm{M} \mathrm{H} \mathrm{H}_{2} \mathrm{SO}_{4}$ was used as the electrolyte, $\mathrm{Ag} / \mathrm{AgCl}$ (saturated $\mathrm{KCl}$ ) and a graphite rod were used as the reference and counter electrodes, respectively

HER mechanism of P-Mo-N. It is found that the as-prepared $\mathrm{Mo}_{2} \mathrm{~N}, \mathrm{P}-\mathrm{Mo}-\mathrm{N}$ with $10 \mathrm{wt} \% \mathrm{P}$, catalyst owns numerous exposed crystal faces, which could reduce its activity in air and lower the Mo-H bonds. This is proven to effectively catalyze water splitting for $\mathrm{H}_{2}$ production whose performance is superior over most of state-of-art catalysts reported in the literature ${ }^{25,37,41}$. Furthermore, the $\mathrm{P}$ element doping boosts the HER performance greatly and the enhancement should be clarified. In realistic water electrocatalysis, two vital parameters, i.e. interfacial property of catalyst/solution and the intrinsic nature of the catalyst, determine the final performance $18,21,37,61$. Thus, the interface properties were firstly studied to investigate the improvement shown by $\mathrm{P}$ doping. Four solutions with different $\mathrm{pH}$ values were chosen for this purpose.

As shown in Fig. 4a, the polarization curves of the $\mathrm{P}-\mathrm{Mo}-\mathrm{N}$ sample in the four varying $\mathrm{pH}$ solutions present different patterns. Typically, in the $0.5 \mathrm{M} \mathrm{H}_{2} \mathrm{SO}_{4}$ media ( $\mathrm{pH} 0$ ), the catalyst exhibits the best electrocatalytic performance, followed by that in $0.05 \mathrm{M} \mathrm{H}_{2} \mathrm{SO}_{4}(\mathrm{pH} 1), 0.5 \mathrm{M} \mathrm{Na}_{2} \mathrm{SO}_{4} \quad(\mathrm{pH}$-6.8) and $0.1 \mathrm{mM} \mathrm{NaOH}(\mathrm{pH} \sim 10)$, suggesting that more free $\mathrm{H}^{+}$can help obtain a high $\mathrm{H}_{2}$ evolution performance. Moreover, at the current density of $10 \mathrm{~mA} / \mathrm{cm}^{2}$, we measured the corresponding potential values: 135,128 , and $100 \mathrm{mV}$ for $0.1 \mathrm{mM} \mathrm{NaOH}, 0.5 \mathrm{M} \mathrm{Na}_{2} \mathrm{SO}_{4}$, and $0.05 \mathrm{M} \mathrm{H}_{2} \mathrm{SO}_{4}$, respectively. There is a double electrode layer (DEL) at the solid|liquid interface, this can be attributed to different $\mathrm{H}^{+}$concentrations will inducing a varied $\mathrm{H}^{+}$adsorption or arrangement ${ }^{62}$. The $0.1 \mathrm{mM} \mathrm{NaOH}$ condition for $\mathrm{P}-\mathrm{Mo}-\mathrm{N}$ HER presented in Fig. $4 \mathrm{a}$ demonstrated a better performance than bare $\mathrm{Mo}_{2} \mathrm{~N}$ in $0.5 \mathrm{M} \mathrm{H}_{2} \mathrm{SO}_{4}$ (Fig. 3a), suggesting the $\mathrm{P}$ doping can induce a favorable $\mathrm{H}^{+}$arrangement for HER in the DEL even in a low $\mathrm{H}^{+}$concentration solution. The corresponding EIS spectrum 

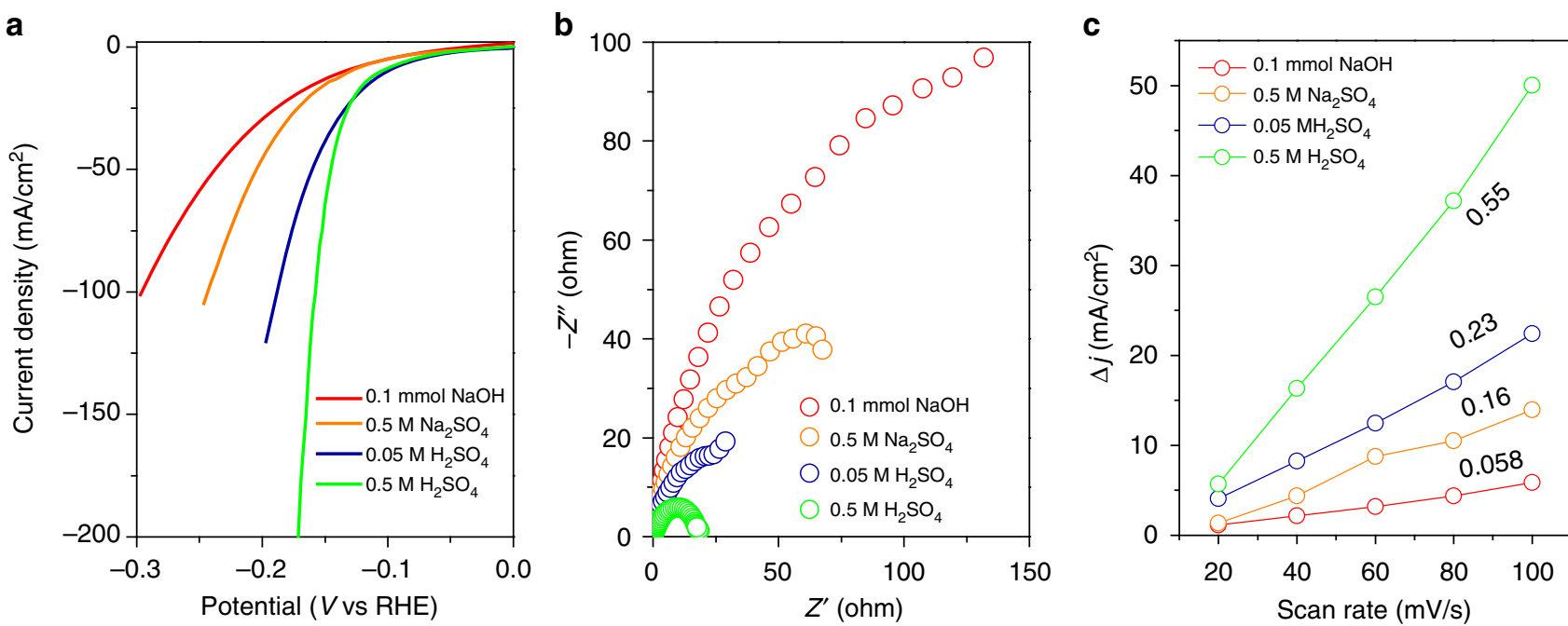

Fig. 4 Water electrolysis in different $\mathrm{pH}$ solutions. a HER electrocatalysis on $\mathrm{P}-\mathrm{Mo}-\mathrm{N}$ catalyst in the different $\mathrm{pH}$ solutions: $0.1 \mathrm{mM} \mathrm{NaOH}, 0.5 \mathrm{M} \mathrm{Na} 2 \mathrm{SO}_{4}$ $0.05 \mathrm{M} \mathrm{H}_{2} \mathrm{SO}_{4}$, and $0.5 \mathrm{M} \mathrm{H}_{2} \mathrm{SO}_{4}$; b the electrochemical impedance spectra (EIS) of P-Mo- $\mathrm{N}$ sample under the four solution: $0.1 \mathrm{mM}$ NaOH, $0.5 \mathrm{M}$ $\mathrm{Na}_{2} \mathrm{SO}_{4}, 0.05 \mathrm{M} \mathrm{H}_{2} \mathrm{SO}_{4}$, and $0.5 \mathrm{M} \mathrm{H}_{2} \mathrm{SO}_{4}$, the bias voltage is set to be $-100 \mathrm{mV}$; c the plots of $\Delta j$ at $-0.1 \mathrm{~V}$ vs. RHE against the scan rate, the corresponding slopes are also shown, the corresponding CV curves in the region of $-0.2 \sim 0.0 \mathrm{~V}$ vs. RHE are given in Supplementary Figure 24. Please note that the dates of $0.5 \mathrm{M} \mathrm{H}_{2} \mathrm{SO}_{4}$ condition are obtained from above results, not the new dates

in Fig. $4 \mathrm{~b}$ in different $\mathrm{pH}$ solutions shows that similar trends can be found. For studying the adsorption behavior of reaction species in the DEL, a bias potential of $-100 \mathrm{mV}$ (after this potential, the $\mathrm{H}_{2}$ evolution will start ${ }^{62}$ ) was used according to the polarization curves. Supplementary Table 5 shows the corresponding fitted resistance values based on the fitting circuit (Supplementary Figure 19b). Obviously, the $\mathrm{R}_{\mathrm{ct}}$ in the $0.5 \mathrm{M}$ $\mathrm{H}_{2} \mathrm{SO}_{4}$ solution gives the smallest value, and it increases with the elevated $\mathrm{pH}$, suggesting that more free $\mathrm{H}^{+}$in the electrolyte will be suitable for DEL formation with a low resistance. The EIS spectrum of bare $\mathrm{Mo}_{2} \mathrm{~N}$ catalyst was also conducted under the same condition with an $R_{\mathrm{ct}}$ value of $62.3 \mathrm{ohm}$, further confirming that the $\mathrm{P}$ doping can induce a suitable $\mathrm{H}^{+}$adsorption and then $\mathrm{a}$ low resistance DEL. To get more information about the DEL, the electrocatalytic reaction area was further carried out according to the $\mathrm{CV}$ curves under the potential range of -0.2 to $0 \mathrm{~V}$ as shown in Supplementary Figure 25. The $\mathrm{C}_{\mathrm{dl}}$ values were calculated to be $275,115,80$, and $29 \mathrm{mF} / \mathrm{cm}^{2}$ for $0.5 \mathrm{M} \mathrm{H}_{2} \mathrm{SO}_{4}, 0.05 \mathrm{M} \mathrm{H}_{2} \mathrm{SO}_{4}, 0.5$ $\mathrm{M} \mathrm{Na}_{2} \mathrm{SO}_{4}$, and $0.1 \mathrm{mM} \mathrm{NaOH}$, respectively, further validating the above results, that is, more free $\mathrm{H}^{+}$can be adsorbed by the $\mathrm{P}$ doped surface of $\mathrm{Mo}_{2} \mathrm{~N}$.

The intrinsic nature of the $\mathrm{P}$ doped $\mathrm{Mo}_{2} \mathrm{~N}$ was next investigated for understanding the HER enhancement. Density functional theory (DFT) calculations were carried out. Owing to the more exposed facets of the synthesized $\mathrm{Mo}_{2} \mathrm{~N}$ sample, four main crystal face models, (112), (200), (220), and (312) with the $\mathrm{N}$ replaced by $\mathrm{P}$ were established as shown in Supplementary Figure 26 and Fig. 5a-b. For studying the reaction centers, the elements for proton adsorption were also labeled (Supplementary Figure 26). The computational $\mathrm{H}$ adsorption free energy values on different reaction centers in different surfaces of the bare $\mathrm{Mo}_{2} \mathrm{~N}$ and $\mathrm{P}$ doped $\mathrm{Mo}_{2} \mathrm{~N}$ samples are summarized as given in Supplementary Table 6-7 and Fig. 5c. Typically, for the undoped sample, the (200) facet gives a good $\mathrm{H}$ adsorption result either on exposed N center or Mo center. However, the Mo atoms in (200) surface can be oxidized easily and then the bare $\mathrm{Mo}_{2} \mathrm{~N}$ always gives a low HER performance (Fig. 3a). Exposing more facets with lots of grain boundaries can stabilize (200) facet and induce more reaction sites, and then the $\mathrm{Mo}_{2} \mathrm{~N}$ sample with a grain boundary displays a better HER performance than the one with a single exposed surface. For the P doped sample, the P sites in two facets of (112) and (312) give suitable HER reaction sites with the relative small $\mathrm{H}$ adsorption free energy values of 0.04 and $0.08 \mathrm{eV}$, respectively. Figure $5 c$ clearly shows that the hydrogen adsorption free energy $\left(G\left({ }^{*} \mathrm{H}\right)\right)$ gives a very small $G\left({ }^{\star} \mathrm{H}\right)$ value for the $\mathrm{P}-\mathrm{Mo}-\mathrm{N}$ sample at $\mathrm{P}$ sites, whereas the Mo sites or $\mathrm{N}$ sites in doped or bare samples show the strong water adsorption ability and consequent a weak desorption behavior. Supplementary Figure 27 and Fig. 5d, e give the contrastive N-p, P-p and Mo-d orbital density of states (DOS) in four facets of bare and doped $\mathrm{Mo}_{2} \mathrm{~N}$ samples. Obviously, the $\mathrm{p}$ orbitals of $\mathrm{P}$ atom in all conditions show a right shift compared to $\mathrm{N}$ atoms, suggesting that the more anti-bonding orbital of the $\mathrm{P}$ atom will hybridize with the s orbital of the $\mathrm{H}$ atom, and then weaken the $\mathrm{G}\left({ }^{\star} \mathrm{H}\right)$ value. Meanwhile, for the Mo atom, an opposite tendency can be found, further confirming that the P doping is good for the HER process. Moreover, the work functions $\left(\mathrm{W}_{\mathrm{f}}\right)$ based on ultravioletphotoelectron spectra (UPS) in Fig. 5f and Supplementary Figure 28 were calculated to be 4.8 and $4.53 \mathrm{eV}$ for $\mathrm{Mo}_{2} \mathrm{~N}$ and $\mathrm{P}-\mathrm{Mo}_{2} \mathrm{~N}$, respectively. Note that a small $\mathrm{W}_{\mathrm{f}}$ of a catalyst will be helpful for electrons migrating through the sample and then assist with a better activity. Here a low $\mathrm{W}_{\mathrm{f}}$ further confirms that the $\mathrm{P}$ doping can promote electron transfer and enhance chemical activity.

\section{Discussion}

We describe here an air-stable $\mathrm{Mo}_{2} \mathrm{~N}$ electrocatalyst prepared from a violent solid-state reaction of ethanediamine and $\mathrm{MoO}_{3}$ by utilizing the strategy discussed above. Owing to the several reaction sites, the $\mathrm{Mo}_{2} \mathrm{~N}$ was achieved with several exposed crystal facets, which lower the active Mo atom number. Moreover, the by-product of abundant crystal boundaries was beneficial to the HER performance. BP was used for $\mathrm{P}$ doping and the obtained $\mathrm{P}-\mathrm{Mo}-\mathrm{N}$ showed an enhanced HER activity compared with bare $\mathrm{Mo}_{2} \mathrm{~N}$. Experimental and computational results collectively confirmed more reaction sites provided by $\mathrm{P}$ doping, a lower carriers/ protons migration resistance across the catalyst/solution interface, as well as a suitable hydrogen adsorption free energy. Such a method for ensuring uniform multi-site solid-state reaction can be extended to synthesis of other materials, and thus enrich earthabundant elements based catalysts with satisfactory activity. Moreover, the P doping strategy can help us understand more 
a

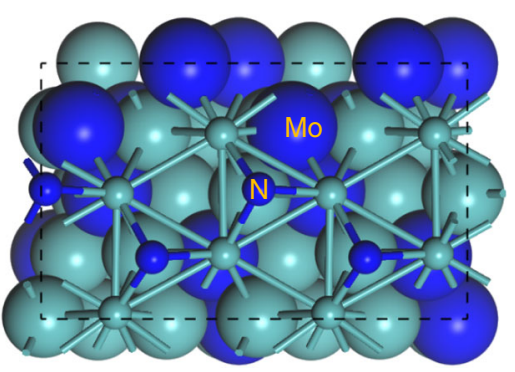

C

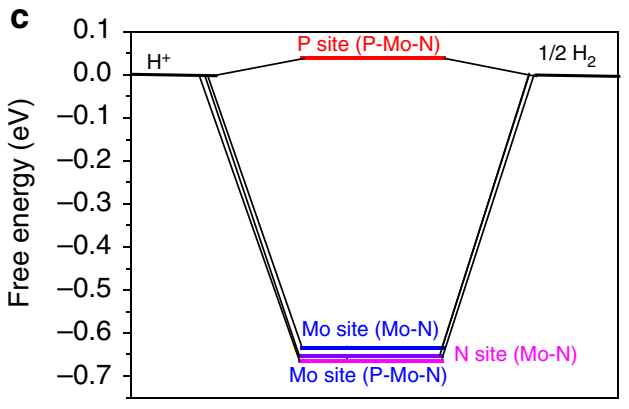

Reaction coordinate

e

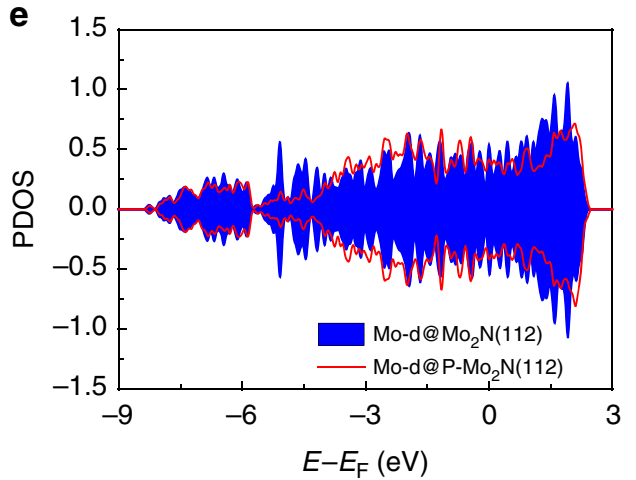

b

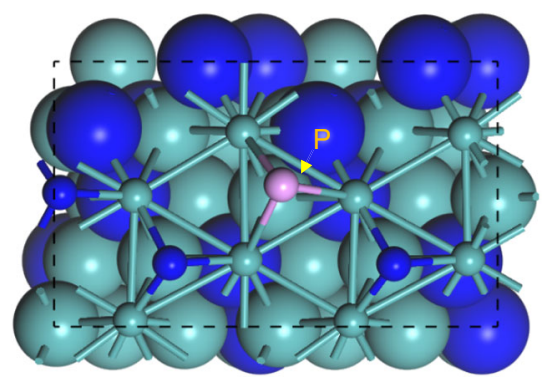

d

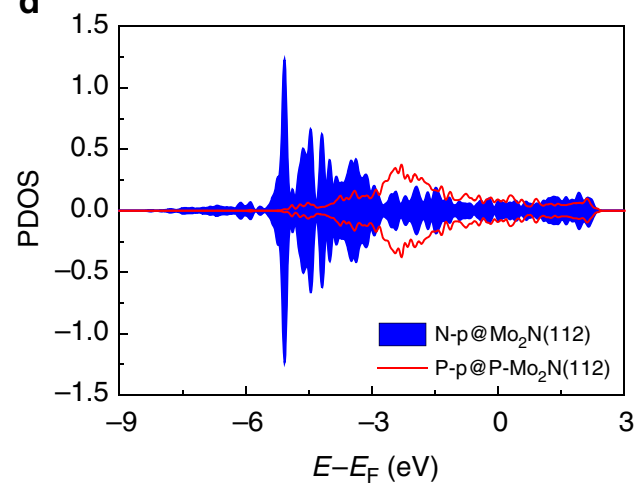

$\mathbf{f}$

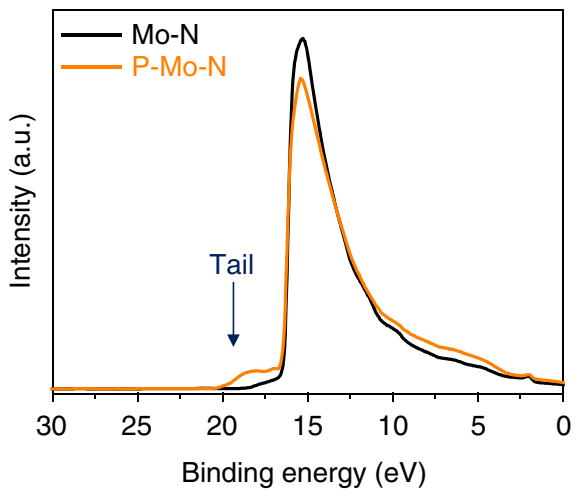

Fig. 5 Electronic structure of $\mathrm{Mo}_{2} \mathrm{~N}$ and $\mathrm{P}-\mathrm{Mo}_{2} \mathrm{~N}$. DFT calculation: a model of bare $\mathrm{Mo}_{2} \mathrm{~N}$ (112) facet; $\mathbf{b}$ model of $\mathrm{P}$ doped $\mathrm{Mo}_{2} \mathrm{~N}$ (112) surface, one $\mathrm{N}$ atom was replaced by one $\mathrm{P}$ atom; the blue, cyan, and pink spheres are $\mathrm{Mo}, \mathrm{N}$, and $\mathrm{P}$ atoms, respectively. The dotted gray box in $\mathbf{a}$ or $\mathbf{b}$ is the framework of the model. c Free energy diagrams for hydrogen adsorption at different sits ( $\mathrm{Mo}, \mathrm{N}$, and $\mathrm{P}$ ) on the (112) surface of bare $\mathrm{Mo}_{2} \mathrm{~N}$ and $\mathrm{P}$ doped $\mathrm{Mo}_{2} \mathrm{~N}$; computational densities of states (DOS) of (d) N-p orbital in bare $\mathrm{Mo}_{2} \mathrm{~N}$ (112) surface, $\mathrm{P}$-p orbital in $\mathrm{P}$ doped $\mathrm{Mo}_{2} \mathrm{~N}$ (112) surface and e Mo-d orbital in bare and doped $\mathrm{Mo}_{2} \mathrm{~N}$ (112) surface. $\mathbf{f}$ Ultraviolet-photoelectron spectra of $\mathrm{Mo}_{2} \mathrm{~N}$ and $\mathrm{P}$ doped $\mathrm{Mo}_{2} \mathrm{~N}$ samples. For the sample of $\mathrm{P}$ doped $\mathrm{Mo}_{2} \mathrm{~N}$, a tail can be found as depicted by the blue arrow

about electrocatalytic reaction mechanisms such as HER presented here and also design more doped samples to enhance active site exposure and provide more adsorption and desorption characteristics.

\section{Methods}

Synthesis of Mo-N. In a typical synthesis, $0.5 \mathrm{~g} \mathrm{MoO}_{3}$ and a certain amount of ethanediamine was first mixed and grinded by a quartz mortar, after that, the mixture was moved to a ball mill and further treated thoroughly for $45 \mathrm{~min}$. Then, the uniform mixture was transferred into one vacuum tube furnace and calcinated under $500{ }^{\circ} \mathrm{C}$ for $4 \mathrm{~h}$ in a flowing $\mathrm{N}_{2}$-gas atmosphere. After naturally cooling to room temperature, the product was collected and stored for further use. Please note that without the treatment of the ball mill, an active $\mathrm{Mo}_{2} \mathrm{~N}$ will be generated.

Synthesis of P-Mo-N. In a typical synthesis, $0.3 \mathrm{~g}$ of Mo-N was added into $100 \mathrm{~mL}$ BP solution, the mixture was then placed under vacuum and then stirred for $3 \mathrm{~h}$ to achieve complete adsorption. After that, the product was treated by centrifugation and vacuum drying. The obtained powder was mixed with ethanediamine by one quartz mortar and then moved into the vacuum tube furnace.
After $4 \mathrm{~h} 500^{\circ} \mathrm{C}$ calcination in a flowing $\mathrm{N}_{2}$-gas atmosphere, the product was collected, dried at $80^{\circ} \mathrm{C}$ and stored for further use.

Material characterization. X-ray diffraction (XRD) patterns of the samples were recorded on a Rigaku Smartlab-9 kW instrument using $\mathrm{Cu} \mathrm{Ka} \mathrm{X}$-ray $(\lambda=1.54186 \AA)$ radiation at a scanning rate of $4 \% \mathrm{~min}$ in the region of $2 \theta=$ $10-80^{\circ}$. X-ray photoelectron spectra (XPS) were acquired on a Kratos Axis Ultra DLD spectrometer with $\mathrm{Al} \mathrm{Ka}(h v=1486.6 \mathrm{eV})$ as the excitation source. Transmission electron microscopy (TEM) test was performed on a FEI Tecnai G2 F20 electron microscope at an acceleration voltage of $200 \mathrm{kV}$. Spherical aberration-corrected electron microscope was carried out on a JEM-ARM200F electron microscope (Beijing Zhongkebaice Technology Service Co., Ltd.). The field emission scanning electron microscopy (FESEM) were observed under a SU8020 electron microscopy. Brunauer-Emmett-Teller (BET) surface area analysis was carried out on a Quadrasorb SI-3 equipment.

HER electrode preparation. Typically, $10 \mathrm{mg}$ sample was added into a $50 \mu \mathrm{L}$ isopropanol, $50 \mu \mathrm{L}$ nafion (Nafion 117 solution, Sigma-Aldrich) was dispersed into the above solution. The mixture was first fixated and then treated by an oscillator for about $30 \mathrm{~min}$. After that, the mixture was further treated by ultrasound ca. Six 
hours to form the uniform ink, which was dropped onto glassy carbon electrodes ( $5.61 \mathrm{~mm}$ diameter, disk area: $0.2475 \mathrm{~cm}^{2}$ ) with a mass loading of $0.2 \mathrm{mg} \mathrm{cm}$. The prepared electrodes were naturally dried in air.

Electrochemical characterization. All of the electrochemical tests were performed in the room temperature using a typical three-electrode setup. The graphite rod (5.0 mm, 99.997\% metals basis) and $\mathrm{Ag} / \mathrm{AgCl}$ electrodes were used as the counter and reference electrodes, respectively. The electrolyte was $0.5 \mathrm{M} \mathrm{H}_{2} \mathrm{SO}_{4}$ solution. A Zennium Zahner electrochemical workstation was used for the electrocatalytic measurements. Before the test, the as-prepared anodes were activated by a chronopotentiometry scan with the $-30 \mathrm{~mA} \mathrm{~cm}^{-2}$ current density for $2 \mathrm{~h}$. The Tafel slopes were obtained from the polarization curves by plotting overpotential against $\log$ (current density). The steady-state activity was evaluated by chronopotentiometry measurements under different potentials. Please note that the scan rate for the electrocatalytic measurements was $5 \mathrm{mV} / \mathrm{s}$. The $\mathrm{C}_{\mathrm{dl}}$ was determined by measuring the capacitive current associated with double-layer charging from the scan rate $\mathrm{CV}$-dependence. In our present work, the $\mathrm{CV}$ potential window was chosen to be -0.2 to $0 \mathrm{vs} \mathrm{Ag} / \mathrm{AgCl}$. The scan rates were 20 , $40,60,80$, and $100 \mathrm{mV} \mathrm{s}^{-1}$. The double-layer capacitance $\left(\mathrm{C}_{\mathrm{dl}}\right)$ was estimated $\Delta j=\left(j_{\text {charge }}-j_{\text {off charge }}\right)$ at $-0.1 \mathrm{~V}$ vs $\mathrm{Ag} / \mathrm{AgCl}$ against the scan rate. The linear slope was twice of the double-layer capacitance $\mathrm{C}_{\mathrm{d} \text {. }}$. EIS measurements were carried out after the HER tests under the different potentials. The ZSim Demo software was used to fit the EIS results. The measured potentials vs. $\mathrm{Ag} / \mathrm{AgCl}$ were converted to the reversible hydrogen electrode (RHE) scale according to the following Nernst equation: $\mathrm{E}_{\mathrm{RHE}}=\mathrm{E}_{\mathrm{Ag} / \mathrm{AgCl}}+0.059 \mathrm{pH}+\mathrm{E}_{\mathrm{Agg} / \mathrm{AgCl}}^{\circ}$, where $\mathrm{E}_{\mathrm{RHE}}$ is the converted potential vs. RHE, $\mathrm{E}^{\circ} \mathrm{Ag} / \mathrm{AgCl}=0.1976$ at $25^{\circ} \mathrm{C}$, and $\mathrm{E}_{\mathrm{Ag} / \mathrm{AgCl}}$ is the experimentally measured potential against $\mathrm{Ag} / \mathrm{AgCl}$ reference.

Computation model and details. The optimized lattice constants of the $\mathrm{Mo}_{2} \mathrm{~N}$ unit cell with $4 / \mathrm{mmm}$ point group were $a=b=4.2627 \AA$ and $c=8.0876 \AA$. Then four types of five-layered (112), (200), (312), and (220) surface with a $15 \AA$ height were cleaved from their bulk phase and the top three layers were allowed to relax. The single-point energy and the geometry optimization were implemented in the Vinnea ab initio software package (VASP) within the framework of density functional theory ${ }^{63}$. The exchange-correlation functional adopted the generalized gradient approximation of the Perdew-Burke-Ernzerhof (GGA-PBE) formula ${ }^{64}$. The projector augmented wave method with a cutoff energy of $520 \mathrm{eV}$ was set. The optimization convergence standards were $10-4 \mathrm{eV}$ for energy and $-0.05 \mathrm{eV} / \AA$ for force. The formation energy $E_{f}$ of different surface and P-doping configurations were calculated by:

$$
E_{f}=\left(E_{\text {total }}-n_{\mathrm{N}} \mu_{\mathrm{N}}-n_{\mathrm{Mo}} \mu_{\mathrm{Mo}}-n_{\mathrm{P}} \mu_{\mathrm{P}}\right) /\left(n_{\mathrm{N}}+n_{\mathrm{Mo}}+n_{\mathrm{P}}\right),
$$

where the $n_{\mathrm{N}}, n_{\mathrm{Mo}}$, and $n_{\mathrm{P}}$ were the total number of $\mathrm{N}, \mathrm{Mo}$, and P atoms and $\mu_{\mathrm{N}}$, $\mu_{\mathrm{Mo}}$ and $\mu_{\mathrm{P}}$ were the chemical potential of the element $\mathrm{N}$, Mo, and P defined from the nitrogen gas molecule, bulk Mo metal and black phosphorus phase. $E_{\text {total }}$ was the total energy of the configuration. For the adsorption free energy of hydrogen atom, it was calculated based on the formula:

$$
G_{* H}=E_{* H}-E_{*}-1 / 2 E_{H_{2}}+0.24,
$$

where the $E_{*_{H}}, E_{*}$, and $E_{H}$ were the total energy of the surface with and without hydrogen adsorption and the hydrogen gas molecule. Then $0.24 \mathrm{eV}$ was added to correct the contribution of the zero-point energy and entropy based on previous report ${ }^{65}$

\section{Data availability}

The data that support the findings of this study are available from the corresponding authors upon reasonable request.

Received: 14 August 2018 Accepted: 26 November 2018

Published online: 12 December 2018

\section{References}

1. Turner, J. A. Sustainable hydrogen production. Science 305, 972-974 (2004).

2. Dresselhaus, M. S. \& Thomas, I. L. Alternative energy technologies. Nature 414, 332-337 (2001).

3. Walter, M. G. et al. Solar water splitting cells. Chem. Rev. 110, 6446-6473 (2010).

4. $\mathrm{Xu}$, J. et al. Boosting the hydrogen evolution performance of ruthenium clusters through synergistic coupling with cobalt phosphide. Energy Environ. Sci. 11, 1819-1827 (2018).

5. Zhou, H. et al. Water splitting by electrolysis at high current densities under 1.6 volts. Energy Environ. Sci. 11, 2858-2864 (2018).
6. Wang, C. et al. Facile synthesis of silk-cocoon S-rich cobalt polysulfide as an efficient catalyst for the hydrogen evolution reaction. Energy Environ. Sci. 11, 2467-2475 (2018)

7. Voiry, D. et al. The role of electronic coupling between substrate and $2 \mathrm{D} \mathrm{MoS}_{2}$ nanosheets in electrocatalytic production of hydrogen. Nat. Mater. 15, 1003-1009 (2016).

8. Mishra, I. K. et al. Hierarchical $\mathrm{CoP} / \mathrm{Ni}_{5} \mathrm{P}_{4} / \mathrm{CoP}$ microsheet arrays as a robust $\mathrm{pH}$-universal electrocatalyst for efficient hydrogen generation. Energy Environ. Sci. 11, 2246-2252 (2018).

9. Yang, Y. et al. Metal surface and interface energy electrocatalysis: fundamentals, performance engineering, and opportunities. Chem 4, 2054-2083 (2018).

10. Laursen, A. B. et al. Climbing the volcano of electrocatalytic activity while avoiding catalyst corrosion: $\mathrm{Ni}_{3} \mathrm{P}$, a hydrogen evolution electrocatalyst stable in both acid and alkali. ACS Catal. 8, 4408-4419 (2018).

11. Anantharaj, S. et al. Shrinking the hydrogen overpotential of $\mathrm{Cu}$ by $1 \mathrm{~V}$ and Imparting ultralow charge transfer resistance for enhanced $\mathrm{H}_{2}$ evolution. ACS Catal. 8, 5686-5697 (2018).

12. Luo, Z. et al. Chemically activating $\mathrm{MoS}_{2}$ via spontaneous atomic palladium interfacial doping towards efficient hydrogen evolution. Nat. Commun. 9, 2120 (2018).

13. Zheng, Y., Jiao, Y., Vasileff, A. \& Qiao, S. Z. The hydrogen evolution reaction in alkaline solution: from theory, single crystal models, to practical electrocatalysts. Angew. Chem. Int. Ed. 57, 7568-7579 (2018).

14. Wang, Z. L. et al. Spatially confined assembly of monodisperse ruthenium nanoclusters in a hierarchically ordered carbon electrode for efficient hydrogen evolution. Angew. Chem. Int. Ed. 57, 5848-5852 (2018).

15. $\mathrm{Li}, \mathrm{H}$. et al. Systematic design of superaerophobic nanotube-array electrode comprised of transition-metal sulfides for overall water splitting. Nat. Commun. 9, 2452 (2018).

16. Xue, Y. et al. Anchoring zero valence single atoms of nickel and iron on graphdiyne for hydrogen evolution. Nat. Commun. 9, 1460 (2018).

17. Xie, $\mathrm{L}$. et al. $\mathrm{A} \mathrm{Ni}(\mathrm{OH})_{2}-\mathrm{PtO}_{2}$ hybrid nanosheet array with ultralow $\mathrm{Pt}$ loading toward efficient and durable alkaline hydrogen evolution. J. Mater. Chem. A 6, 1967-1970 (2018)

18. Feng, J. X., Wu, J. Q., Tong, Y. X. \& Li, G. R. Efficient hydrogen evolution on $\mathrm{Cu}$ nanodots-decorated $\mathrm{Ni}_{3} \mathrm{~S}_{2}$ nanotubes by optimizing atomic hydrogen adsorption and desorption. J. Am. Chem. Soc. 140, 610-617 (2018).

19. Vincent, I. \& Bessarabov, D. Low cost hydrogen production by anion exchange membrane electrolysis: a review. Renew. Sust. Energy Rev. 81, 1690-1704 (2018).

20. Gu, Y. et al. Electronic structure tuning in $\mathrm{Ni}_{3} \mathrm{FeN} / \mathrm{r}-\mathrm{GO}$ aerogel toward bifunctional electrocatalyst for overall water splitting. ACS Nano 12, 245-253 (2018).

21. Wang, H. et al. Electrochemical tuning of $\mathrm{MoS}_{2}$ nanoparticles on threedimensional substrate for efficient hydrogen evolution. ACS Nano $\mathbf{8}$, 4940-4947 (2014)

22. Grønborg, S. S. et al. Visualizing hydrogen-induced reshaping and edge ctivation in $\mathrm{MoS}_{2}$ and Co-promoted $\mathrm{MoS}_{2}$ catalyst clusters. Nat. Commun. 9, 2211 (2018)

23. Yin, X. et al. Quasi-emulsion confined synthesis of edge-rich ultrathin $\mathrm{MoS}_{2}$ nanosheets/graphene hybrid for enhanced hydrogen evolution. Chem. Eur. J. 24, 556-560 (2018).

24. Benson, E. E. et al. Balancing the hydrogen evolution reaction, surface energetics, and stability of metallic $\mathrm{MoS}_{2}$ nanosheets via covalent functionalization. J. Am. Chem. Soc. 140, 441-450 (2018).

25. Huang, Y. et al. Nitrogen-doped porous molybdenum carbide and phosphide hybrids on a carbon matrix as highly effective electrocatalysts for the hydrogen evolution reaction. Adv. Energy Mater. 8, 1701601 (2018).

26. Jin, Y. et al. Preparation of mesoporous $\mathrm{Ni}_{2} \mathrm{P}$ nanobelts with high performance for electrocatalytic hydrogen evolution and supercapacitor. Int. J. Hydrog. Energy 43, 3697-3704 (2018).

27. Gong, M. et al. Nanoscale nickel oxide/nickel heterostructures for active hydrogen evolution electrocatalysis. Nat. Commun. 5, 4695 (2014).

28. Wang, T., Jin, R., Wu, Y., Zheng, J. \& Li, X. Chemical induced fragmentation of MOFs for highly efficient Ni-based hydrogen evolution catalysts. Nanoscale Horiz. 3, 218-225 (2018).

29. $\mathrm{Wu}, \mathrm{Z}$. et al. Materials chemistry of iron phosphosulfide nanoparticles: synthesis, solid state chemistry, surface structure, and electrocatalysis for the hydrogen evolution reaction. ACS Catal. 7, 4026-4032 (2018).

30. Zou, X. et al. In situ generation of bifunctional, efficient Fe-based catalysts from mackinawite iron sulfide for water splitting. Chem 4, 1139-1152 (2018).

31. Jiao, Y., Zheng, Y., Davey, K. \& Qiao, S. Z. Activity origin and catalyst design principles for electrocatalytic hydrogen evolution on heteroatom-doped grapheme. Nat. Energy 1, 16130 (2016).

32. Conway, B. E. \& Tilak, B. V. Interfacial processes involving electrocatalytic evolution and oxidation of $\mathrm{H}_{2}$, and the role of chemisorbed $\mathrm{H}$. Electrochim. Acta 47, 3571-3594 (2002). 
33. Li, Y. et al. $\mathrm{MoS}_{2}$ nanoparticles grown on graphene: an advanced catalyst for the hydrogen evolution reaction. J. Am. Chem. Soc. 133, 7296-7299 (2011).

34. Jaramillo, T. F. et al. Identification of active edge sites for electrochemical $\mathrm{H}_{2}$ evolution from $\mathrm{MoS}_{2}$ nanocatalysts. Science 317, 100-102 (2007).

35. Lv, C. et al. Ultrafast synthesis of molybdenum carbide nanoparticles for efficient hydrogen generation. J. Mater. Chem. A 5, 22805-22812 (2017).

36. Wu, Z. et al. $\mathrm{MoS}_{2}-\mathrm{MoP}$ heterostructured nanosheets on polymer-derived carbon as an electrocatalyst for hydrogen evolution reaction. J. Mater. Chem. A 6, 616-622 (2018).

37. Yan, H. et al. Holey reduced graphene oxide coupled with an $\mathrm{Mo}_{2} \mathrm{~N}-\mathrm{Mo}_{2} \mathrm{C}$ heterojunction for effcient hydrogen evolution. Adv. Mater. 30, 1704156 (2018).

38. Zhang, X. et al. Molybdenum phosphide/carbon nanotube hybrids as $\mathrm{pH}$ universal electrocatalysts for hydrogen evolution reaction. Adv. Funct. Mater. 28, 1706523 (2018).

39. Lv, Z. et al. Well-dispersed molybdenum nitrides on a nitrogen-doped carbon matrix for highly efficient hydrogen evolution in alkaline media. J. Mater. Chem. A 5, 20932-20937 (2017).

40. Chen, Y.-Y. et al. Pomegranate-like N, P-doped $\mathrm{Mo}_{\mathrm{C}} @ \mathrm{C}$ nanospheres as highly active electrocatalysts for alkaline hydrogen evolution. ACS Nano 10, 8851-8860 (2016).

41. Ma, L., Ting, L. R. L., Molinari, V., Giordano, C. \& Yeo, B. S. Efficient hydrogen evolution reaction catalyzed by molybdenum carbide and molybdenum nitride nanocatalysts synthesized via the urea glass route. $J$. Mater. Chem. A 3, 8361-8368 (2015).

42. Sun, Y. et al. Strong electronic interaction in dual-cation-incorporated $\mathrm{NiSe}_{2}$ nanosheets with lattice distortion for highly effcient overall water splitting. Adv. Mater. 30, 1802121 (2018).

43. Anjum, M. A. R. \& Lee, J. S. Sulfur and nitrogen dual-doped molybdenum phosphide nanocrystallites as an active and stable hydrogen evolution reaction electrocatalyst in acidic and alkaline media. ACS Catal. 7, 3030-3038 (2017).

44. Wu, Y. et al. Electron density modulation of $\mathrm{NiCO}_{2} \mathrm{~S}_{4}$ nanowires by nitrogen incorporation for highly efficient hydrogen evolution catalysis. Nat. Commun. 9, 1425 (2018).

45. Guan, C. et al. Hollow Mo-doped CoP nanoarrays for efficient overall water splitting. Nano Energy 48, 73-80 (2018).

46. Wei, $\mathrm{H}$. et al. Molybdenum carbide nanoparticles coated into the graphene wrapping $\mathrm{N}$-doped porous carbon microspheres for highly efficient electrocatalytic hydrogen evolution both in acidic and alkaline media. Adv. Sci. 5, 1700733 (2018).

47. Wang, J., Wei, Z., Mao, S., Li, H. \& Wang, Y. Highly uniform Ru nanoparticles over N-doped carbon: $\mathrm{pH}$ and temperature-universal hydrogen release from water reduction. Energy Environ. Sci. 11, 800-806 (2018).

48. Ji, L. et al. N, P-doped molybdenum carbide nanofibers for efficient hydrogen production. ACS Appl. Mater. Interfaces 10, 14632-14640 (2018).

49. Zhang, J. et al. Facile one-step synthesis of phosphorus-doped $\mathrm{CoS}_{2}$ as efficient electrocatalyst for hydrogen evolution reaction. Electrochim. Acta 259, 955-961 (2018).

50. Gu, H., Fan, W. \& Liu, T. Phosphorus-doped $\mathrm{NiCO}_{2} \mathrm{~S}_{4}$ nanocrystals grown on electrospun carbon nanofibers as ultra-efficient electrocatalysts for the hydrogen evolution reaction. Nanoscale Horiz. 2, 277-283 (2017).

51. Shi, Z. et al. Phosphorus- $\mathrm{Mo}_{2} \mathrm{C} @$ carbon nanowires toward efficient electrochemical hydrogen evolution: composition, structural and electronic regulation. Energy Environ. Sci. 10, 1262-1271 (2017).

52. Sun, A., Shen, Y., Wu, Z. \& Wang, D. N-doped MoP nanoparticles for improved hydrogen evolution. Int. J. Hydrog. Energy 42, 14566-14571 (2017).

53. Xie, J. et al. Controllable disorder engineering in oxygen-incorporated $\mathrm{MoS}_{2}$ ultrathin nanosheets for efficient hydrogen evolution. J. Am. Chem. Soc. 135, 17881-17888 (2013).

54. Li, G. et al. All the catalytic active sites of $\mathrm{MoS}_{2}$ for hydrogen evolution. J. Am. Chem. Soc. 138, 16632-16638 (2016).

55. Xie, J. et al. Defect-rich $\mathrm{MoS}_{2}$ ultrathin nanosheets with additional active edge sites for enhanced electrocatalytic hydrogen evolution. Adv. Mater. 25, 5807-5813 (2013).

56. Kong, L. et al. g- $\mathrm{C}_{3} \mathrm{~N}_{4}$ Loading black phosphorus quantum dot for efficient and stable photocatalytic $\mathrm{H}_{2}$ generation under visible light. Adv. Funct. Mater. 28, 1800668 (2018).

57. Yan, J. et al. Black phosphorus-based compound with few layers for photocatalytic water oxidation. ChemCatChem 10, 3424-3428 (2018).
58. Yan, J. et al. Nitrogen promoted molybdenum dioxide nanosheets for electrochemical hydrogen generation. J. Mater. Chem. A 6, 12532-12540 (2018).

59. Xiao, P. et al. Molybdenum phosphide as an efficient electrocatalyst for the hydrogen evolution reaction. Energy Environ. Sci. 7, 2624-2629 (2014).

60. Yue, Q. et al. MoP is a novel, noble-metal-free cocatalyst for enhanced photocatalytic hydrogen production from water under visible light. J. Mater. Chem. A 3, 16941-16947 (2015).

61. Yan, J. et al. Fe (III) doped $\mathrm{NiS}_{2}$ nanosheet: a highly efficient and low-cost hydrogen evolution catalyst. J. Mater. Chem. A 5, 10173-10181 (2017).

62. Ledezma-Yanez, I. et al. Interfacial water reorganization as a pH-dependent descriptor of the hydrogen evolution rate on platinum electrodes. Nat. Energy 2, 17031 (2017).

63. Kresse, G. \& Furthmüller, J. Efficient iterative schemes for ab initio totalenergy calculations using a plane-wave basis set. Phys. Rev. B: Condens. Matter Mater. Phys. 54, 11169-11186 (1996).

64. Monkhorst, H. J. \& Pack, J. D. Special points for Brillouin-zone integrations. Phys. Rev. B 13, 5188-5192 (1976).

65. Tang, Q. \& Jiang, D. Mechanism of hydrogen evolution reaction on $1 \mathrm{~T}-\mathrm{MoS}_{2}$ from first principles. ACS Catal. 6, 4953-4961 (2016).

\section{Acknowledgements}

We thank the support from the National Key Research Program of China (2017YFA0204800, 2016YFA0202403), Natural Science Foundation of China (No. 21603136, 91733301), the National Science Basic Research Plan in Shaanxi Province of China (2017JM2007), the Changjiang Scholar and Innovative Research Team (IRT_14R33). The 111 Project (B14041), the Fundamental Research Funds for the Central Universities (GK201602007, 2018CSLZ011), and the Chinese National 1000Talent-Plan program are also acknowledged. T.Y.M. acknowledges the support from Australian Research Council (ARC) through Discovery Early Career Researcher Award (DE150101306) and Linkage Project (LP160100927).

\section{Author contributions}

J.Y. and T.M. conceived and designed the experiments. J.Y., L.K., J.W., and X.H. carried out material synthesis, performed physical, and chemical characterization, and conducted the electrochemical measurements. J.Y., T.M., S.L., and S.-T.L. performed data analysis. Y.J. and Y.L. performed all the DFT calculations. All authors discussed the results and cowrote the paper.

\section{Additional information}

Supplementary information accompanies this paper at https://doi.org/10.1038/s42004018-0097-9.

Competing interests: The authors declare no competing interests.

Reprints and permission information is available online at http://npg.nature.com/ reprintsandpermissions/

Publisher's note: Springer Nature remains neutral with regard to jurisdictional claims in published maps and institutional affiliations.

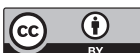

Open Access This article is licensed under a Creative Commons Attribution 4.0 International License, which permits use, sharing adaptation, distribution and reproduction in any medium or format, as long as you give appropriate credit to the original author(s) and the source, provide a link to the Creative Commons license, and indicate if changes were made. The images or other third party material in this article are included in the article's Creative Commons license, unless indicated otherwise in a credit line to the material. If material is not included in the article's Creative Commons license and your intended use is not permitted by statutory regulation or exceeds the permitted use, you will need to obtain permission directly from the copyright holder. To view a copy of this license, visit http://creativecommons.org/ licenses/by/4.0/.

(C) The Author(s) 2018 